\title{
Participación comunitaria, patrimonio cultural e identidad. Estrategia educativa para la apropiación del conocimiento en la población de Taratara, Venezuela
}

\author{
Miguel Zavala-Reyes \\ Andrés-Eloy Reyes
}

\section{Introducción}

Desde la creación del Parque Arqueológico y Paleontológico Taimataima en el Municipio Colina, estado Falcón de la República Bolivariana de Venezuela, el Instituto de Patrimonio Cultural (IPC) generó ciertas expectativas en las comunidades vinculadas con la mejora en su calidad de vida y se comprometió a crear organismos de autogestión para que la comunidad administrara el parque. Esta propuesta se consideró una oportunidad para afianzar el sentido de pertenencia de la comunidad con su recurso patrimonial, así se confirma lo que señala García-Valecillo (2007) sobre que el Estado moderno se apropia del término educación cultural, considerado como el conjunto de relaciones y prácticas que los individuos y grupos humanos efectúan para construir y modificar el entorno y elaborar las formas de autorrepresentación de la sociedad.

Los organismos internacionales han orientado acciones para la unificación de criterios acerca de la conservación y el rescate del patrimonio. La Carta de Atenas (lcomos, 1931) marca la pauta e inicia la reflexión sobre este tema. La Convención de la Haya para la protección de bienes culturales en caso de conflicto armado (Unesco, 1954) incluye los conceptos: patrimonio común, bienes culturales, y la significación universal de las manifestaciones del patrimonio cultural. La Carta de Venecia (lcomos, 1964) relaciona los bienes culturales con el conjunto urbano o rural. La Convención sobre la Protección del Patrimonio Mundial Cultural y Natural (Unesco, 1972) establece el concepto "patrimonio de la humanidad", mientras que la Conferencia Mundial sobre Políticas Culturales, Mondiacult (Unesco, 1982), sentó precedente en la relación cultura y desarrollo, por cuanto el patrimonio permite a los pueblos promover su identidad, y defender su soberanía e independencia.

En Venezuela se han ratificado los acuerdos internacionales, tal como se deriva del principio general de Derecho Público conocido como carácter supranacional de las normas internacionales, así, el Poder Legislativo sanciona la Ley Aprobatoria de la Convención sobre la Protección del Patrimonio Mundial, Cultural y Natural Unesco (1990) y la Ley Aprobatoria de la Convención para la Salvaguarda del Patrimonio Cultural Inmaterial Unesco (2006). Aunado a esto, en 1993 ya se había promulgado en lo nacional la Ley de Protección y Defensa del Patrimonio Cultural como instrumento orgánico que estable-

* Cómo citar este artículo: Zavala-Reyes, M. y Reyes, A.-E. (2017). Participación comunitaria, patrimonio cultural e identidad. Estrategia educativa para la apropiación del conocimiento en la población de Taratara, Venezuela. Apuntes, 30(1), 22-35. https://doi.org/10.11144/Javeriana.apc30-1.pcpc 


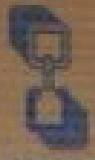

Universidad Nacional Exporimental

Francisco de Miranda UNEFW

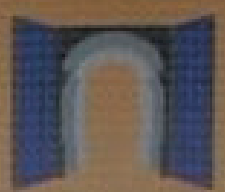

MUSEOS $\cong$ UNEFM

$8=1=$

\section{CRUXENT Y EL PRIMER HOMBRE AMERICANO EN FALCÓN}

U na excavación en Taima-Taima ubicada en el estado Falcón, proyectó al mundo hacia1976, cvidencias de la presencia del hombre americano con una data de más de 13 mil antos, A.P. (antes del presente) Hurgando estas tierras, el cientifico, José Maria Cruxent, halló artefactos líticos del Complejo El Jobo en asociación directa con los restos despedazados de un joven mastodonte especie Haplomastodon waringi, que daba cuenta de la presencia de cazadores recolectores, y de esta manera el surgimiento de una teoria sobre el poblamiento temprano de Venezuela y del continente americano desde el norte al sur. Los hallazgos en el yacimiento de Taima-taima ubicado a 2,5 Km al noreste de la población de Taratara del municipio Colina, mostraron los fósiles de una fauna del pleistoceno superior en un manantial al que los animales posiblemente acudian en búsqueda de agua convirtiendo el lugar en matadero. Alli se encontró la punta de flecha lítica situada dentro de la cavidad del área púbica derecha del mastodonte. A partir de aquí se hicieron análisis radiocarbónicos en ramas de madera del lugar, dio una data de 13 mil años antes del presente, fecha significativa por indicar que es anterior al Complejo Clovis en Norteamérica en Estados Unidos la edad radiocarbónica del Clovis se encuentra entre los 11.500 y 11.000 años A.P, esta fecha coloca entonces al Complejo El Jobo de Taimataima en una posición significativa temporal sobre el Clovis. La data de 13 mil años demuestra que en el norte de Venezuela existia por lo menos un milenio y medio antes del conocido Complejo Clovis de Norteamérica, un grupo de cazadores de macrofauna de tradición tecnológica completamente distinta al Clovis. En esta oportunidad se rememora esta importante investigación encabezada por Cruxent, a través de la exhibición de las piezas fósiles de grandes animales de la colección de la Universidad Nacional Experimental Francisco de Miranda.

POR SU VALOR COMO YACIMIENTO PALENTOLOGICO QUE DEMOSTRO ANTE EL MUNDO LA PRESENCIA HUMANA EN EL CONTINENTE AMERICANO. TAIMA-TAIMA FUE DECLARADO EN GACETA OFICLAL N*35923, BIEN DE INTERES CULTURAL DE VENEZUELA EN 1996.

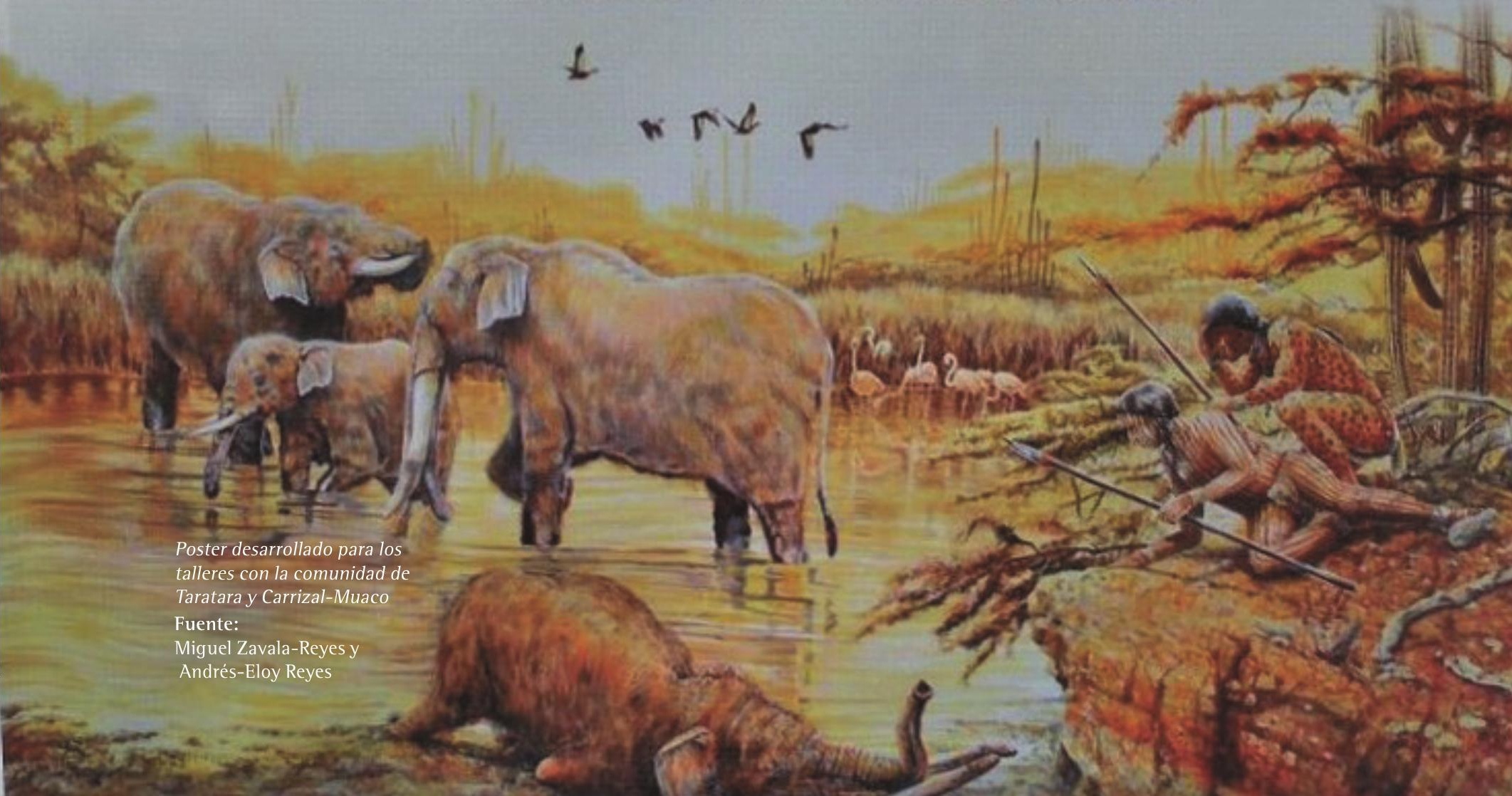




\title{
Participación comunitaria, patrimonio cultural e identidad. Estrategia educativa para la apropiación del conocimiento en la población de Taratara, Venezuela
}

\author{
Community Participation, Cultural Heritage, and ldentity. Educational Strategy
}

for Knowledge Appropriation in the Population of Taratara, Venezuela

Participação comunitária, património cultural e identidade. Estratégia educacional

para a apropriação do conhecimento na população de Taratara-Venezuela.

Miguel Zavala-Reyes

zavalareyesmiguel@gmail.com - Universidad Pedagógica Experimental

Profesor especialista en Geografía e Historia, egresado con mención magna cum laude, diplomado en Conservación de Arte Rupestre, artista plástico. Docente de educación media. Asesor en jornadas científicas, ponente en diversos congresos nacionales e internacionales. Desarrolla proyectos de investigación enmarcados en un enfoque interdisciplinario sobre geohistoria local, poblacion originaria en Venezuela para el momento del contacto, ocupaciones humanas del pleistoceno terminal en Venezuela. Integrante del proyecto financiado por el Fonacit: "Reconstrucción paleoclimatica y paleoambiental de la península de Paraguaná a partir de registros sedimentarios de la laguna Santa Rosa: Clima, transformación del paisaje y ocupación humana en los últimos 10.000 años". Entre sus publicaciones se mencionan los artículos: "Palabras vivas de una lengua muerta. Legado arawak - caquetío" y "Registro y documentación de los petroglifos de la quebrada de Chirache - Buenevara, estado Falcón". Reconocido con la primera mención Ensayo del III Premio Nacional de Literatura Rafael María Baralt, otorgado por la Universidad Experimental Rafael María Baralt, Maracaibo, Venezuela.

Andrés-Eloy Reyes

reyes_a12@hotmail.com

Licenciado en Conservación y Restauración de Bienes Culturales Muebles de la Universidad Nacional Experimental Francisco de Miranda, Unefm. Realiza estudios e investigaciones enfocados en el patrimonio cultural, la arqueología y la paleontología, especialmente paleo-arqueología del cuaternario (Taimataima) y paleontología del neogeno de Venezuela (Urumaco), así como el registro de material arqueológico para su conservación y restauración en el Centro de Investigaciones Arqueológicas, Antropológicas y Paleontologicas de la Unefm. Curador en exposiciones museísticas y facilitador de talleres infantiles y juveniles en el área.

Resumen

El Parque Arqueológico y Paleontológico Taimataima, ubicado al este de la ribera caribeña del estado Falcón, en el noroccidente venezolano, se encontraba en avanzado estado de deterioro, sin que las comunidades que integran el área de influencia mostraran algún signo de interés ante tal situación. Se planteó, entonces, implementar estrategias para la valoración del patrimonio natural y cultural, para lo cual se conformó un equipo multidisciplinario con la Universidad Nacional Experimental Francisco de Miranda (Unefm) y los consejos comunales, respaldado por los resultados que obtuvimos de la investigación arqueológica y geohistórica en la zona. Se realizaron unos talleres pedagógicos de apropiación social, diseñados de acuerdo con paradigmas educativos que brindaron herramientas para el cambio en las apreciaciones de los vecinos sobre su riqueza patrimonial. También se organizó una exposición: "Cruxent y el primer hombre americano en Falcón", pionero en la investigación arqueológica de esta región. Los resultados lograron sensibilizar a los vecinos, quienes reconocieron su necesaria participación para alcanzar el rescate del parque, y los consejos comunales manifestaron su propósito de fortalecer su relación con las instituciones patrimoniales competentes y propusieron productos turísticos culturales para una gestión comunitaria.

Palabras clave: patrimonio cultural; participación comunitaria; José María Cruxent; estado Falcón; Taratara

Abstract

The Taimataima Archaeological and Paleontological Park, located to the east of the Caribbean rim of the Falcón state in northwest Venezuela, is in an advanced state of deterioration. The communities that make up the area of influence do not show any sign of interest in such situation, leading us, then, to consider implementing strategies for the valuation of the natural and cultural heritage. We formed a multidisciplinary team with the Universidad Nacional Experimental Francisco de Miranda (UNEFM) and the communal councils, supported by the results we obtained from archaeological and geo-historical research in the area. We carried out several pedagogical workshops of social appropriation, designed according to the educational paradigms, providing tools for the change in the appreciations of the neighbors on their patrimonial wealth. An exhibition was also organized: "Cruxent and the first American man in Falcón," a pioneer in archaeological research in this region. The results were able to sensitize the neighbors, who recognized the need for their participation to achieve the rescue of the park and the communal councils expressed having strengthened their relationship with the competent heritage institutions and proposed cultural tourism products for community management.

Keywords: Cultural heritage; community participation; José María Cruxent; Falcón state; Taratara

Artículo de investigación

Recepción: 1 de junio de 2015

Aceptación: 23 de febrero de 2016

Disponible en línea: 10 de diciembre de 2017

\section{Resumo}

O Parque Arqueológico e Paleontológico de Taimataima, localizado a leste da borda do Caribe do estado de Falcón, no noroeste da Venezuela, está em estado avançado de deterioração, sem que as comunidades que compõem a área de influência mostrem algum sinal de interesse em tal situação, considerando então implementar estratégias para a avaliação do patrimônio natural e cultural. Uma equipe multidisciplinar foi formada com a Universidade Experimental Nacional Francisco de Miranda (UNEFM), os conselhos comunais, apoiados pelos resultados obtidos da pesquisa arqueológica e geohistorical na área. Foram realizadas algumas oficinas pedagógicas de apropriação social, concebidas de acordo com os paradigmas educacionais, fornecendo ferramentas para a mudança nas apreciações dos vizinhos sobre sua riqueza patrimonial. Também foi organizada uma exposição: “Cruxent e o primeiro homem americano em Falcón", um pioneiro na pesquisa arqueológica nesta região. Os resultados foram capazes de sensibilizar os vizinhos, reconhecendo a sua necessária participação para alcançar o resgate do parque e os conselhos comunais que reforçam um relacionamento com as instituições patrimoniais competentes e propõem produtos de turismo cultural para o gerenciamento comunitário.

Palavras-chave: Patrimônio cultural; participação comunitária; José María Cruxent; estado Falcón; Taratara 
ce diversos mecanismos para la conservación del patrimonio consagrado como bien cultural de la nación. De igual manera, la Constitución Nacional de 1999, en el artículo 99, garantiza la protección, preservación, enriquecimiento, conservación y restauración del patrimonio cultural tangible e intangible, y la memoria histórica de la nación.

Sin embargo, se puede apreciar que, aunque el Parque Arqueológico y Paleontológico de Taimataima fue inaugurado en plena fecha de la efervescencia por la conquista de logros en cuanto a lo patrimonial pero no se le dio al proyecto el acompañamiento necesario que permitiera su continuidad en el tiempo, esta fue la razón que nos motivó para indagar en las comunidades que conforman el eje Taratara-Carrizal-Muaco las causas de la situación que atravesaba el parque y la acción desarticulada del liderazgo vecinal ante ella. El diagnóstico que surja de dicha indagación permitirá establecer estrategias para la valoración del patrimonio cultural a través de la participación comunitaria.

De ahí que involucrar la educación como eje transversal permite a las comunidades generar conocimiento, y apropiarse de este patrimonio al construir el arraigo y sentido de pertenencia, que tras una evaluación holística entre comunidad, gobierno, instituciones educativas y de carácter social, se traduce en el rescate cultural del Parque Arqueológico y Paleontológico Taimataima. Es por ello que en el desarrollo de una actividad de reconocimiento e identidad comunitaria a partir del recurso patrimonial, la educación juega un papel relevante como estrategia transformadora para dar respuesta significativa a una comunidad desmotivada que necesita reencontrarse, evaluarse y apropiarse por decisión propia de su patrimonio como valor identitario.

\section{Descripción del área de estudio}

La zona en estudio de esta circunscripción costera ya mencionada conformaba el extinto pueblo de indios de El Carrizal, fundado en 1723 en las sabanas de Taratara, con una población de aproximadamente 900 habitantes. El poblado de Taratara está opuesto al de Carrizal, seccionado por la vía del camino Real, ruta en dinámico movimiento entre la ciudad de Coro y el pueblo de Cumarebo. En el recorrido en sentido este-oeste se encuen-
Figura 1:

Ubicación de la zona de estudio

Fuente:

Elaboración propia

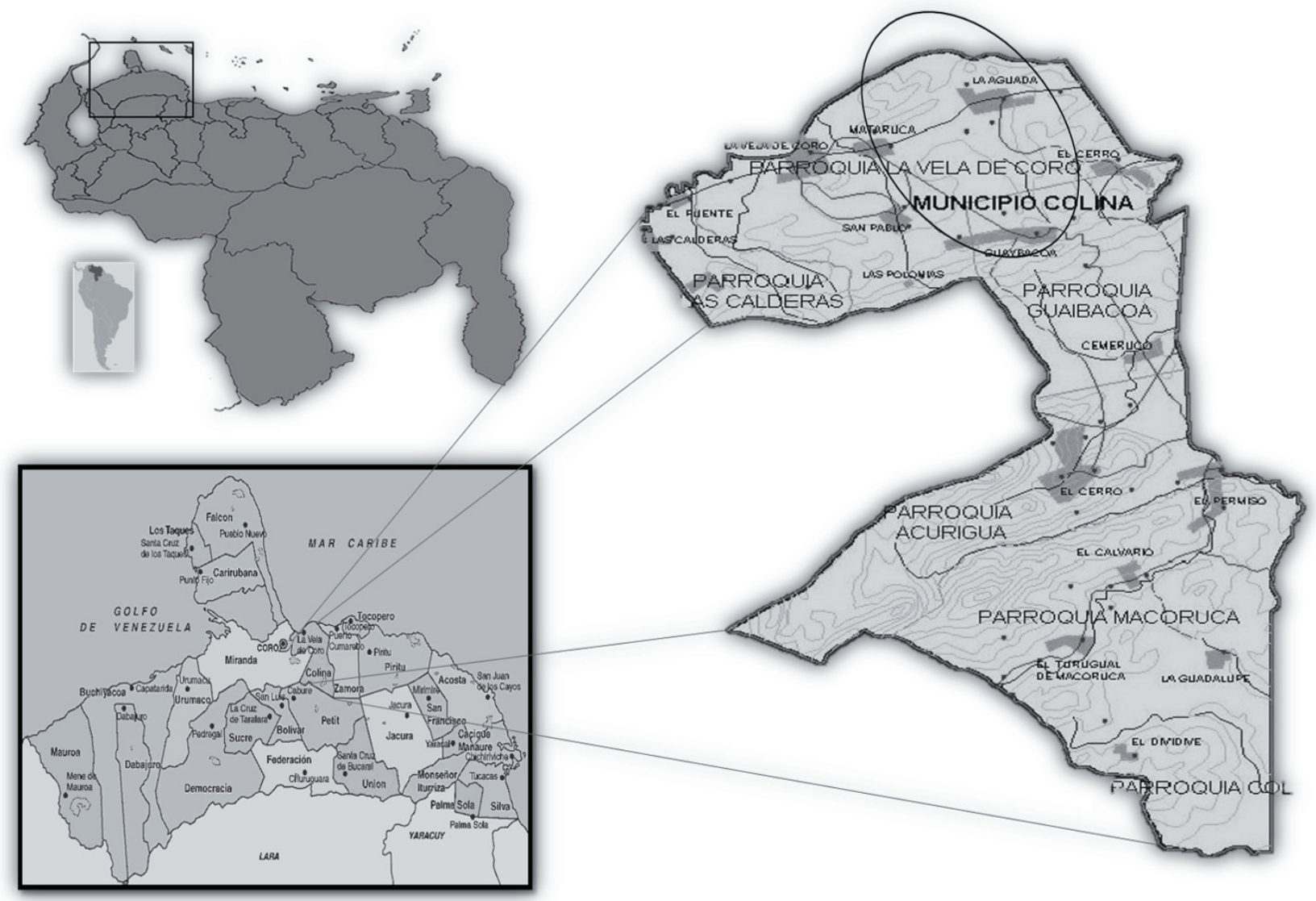


tra la bahía de Cucuruchú, accidentado recorrido que expone la formación geológica Caujarao de importancia antropológica por encontrarse en ella una estación rupestre llamada coloquialmente "Los Letreros", grabados que testimonian el pasado aborigen venezolano.

Continuando el recorrido se encuentra La Peña, formación rocosa a orillas de la playa de Taratara, el sitio arqueológico la piedra del Cacho, hasta encontrarse finalmente con el sitio arqueológico y paleontológico de Muaco. Tierra adentro se ubican el curso de la quebrada Salada, donde se hallaron los restos fósiles de gliptodontes, y el llano de Taratara, caracterizado por la presencia de material cultural y cinegético proveniente de los aborígenes que habitaban la zona tiempo antes del encuentro europeo.

En segundo lugar, se encuentra la punta Taimataima, ubicada en la desembocadura de la quebrada homónima y excavada desde 1961 por el maestro José María Cruxent, quien hizo de este espacio un emblema cultural del país, tras el hallazgo de una variada muestra de fauna pleistocena. Se mencionan como parte del equipo de investigación que logró conformar Cruxent al arqueólogo José Royo y Gómez, quien estuvo desde las primeras excavaciones realizadas en Muaco, y posteriormente los doctores Ruth Gruhn y Alan Bryan, quienes acudieron al lugar con la intención de evaluar las evidencias reportadas.
Entre los hallazgos se cuenta con restos óseos de un mastodonte (stegomastodonwaringi), junto a otros de megafauna, tales como el armadillo gigante (gliptodonte sp.), la pereza gigante (megaterio sp.), el caballo americano (amerhippus), la macrauqenia (xenorhinotherium), la tortuga (quelonia), la llama (paleollama mayor) y el oso de hocico corto (arctoterium). Los fósiles del lugar, de acuerdo con Reyes (2015, p. 98), mantienen su importancia, sobre todo por la contundencia de su significativa data [técnica de radiocarbono $\mathrm{C} 14$, arrojaron fechas de 13.000 AP], que permitió la reconstrucción antropológica de un episodio en la vida cotidiana de antiguos cazadores de Falcón.

Al inicio de la quebrada de Taimataima, donde se levanta actualmente la lona tensil de la exposición in situ del parque, emerge un salobre manantial que se ha convertido en hito turístico dada la importancia arqueo-paleontológica que abre al mundo una ventana sobre el origen del poblamiento temprano en América. De esta área se reservaron 1.480 hectáreas por decreto del ejecutivo para la demarcación de la poligonal que establece los límites del Parque Arqueológico y Paleontológico Taimataima, administrado por el IPC. El área se encuentra hoy bajo régimen de administración especial (Abrae), tras ser declarado Sitio de Interés Cultural según Gaceta Oficial $N^{\circ} 38.206$ de fecha 10 de junio de 2005 (Reyes, 2015, 97).

Elaboración propia

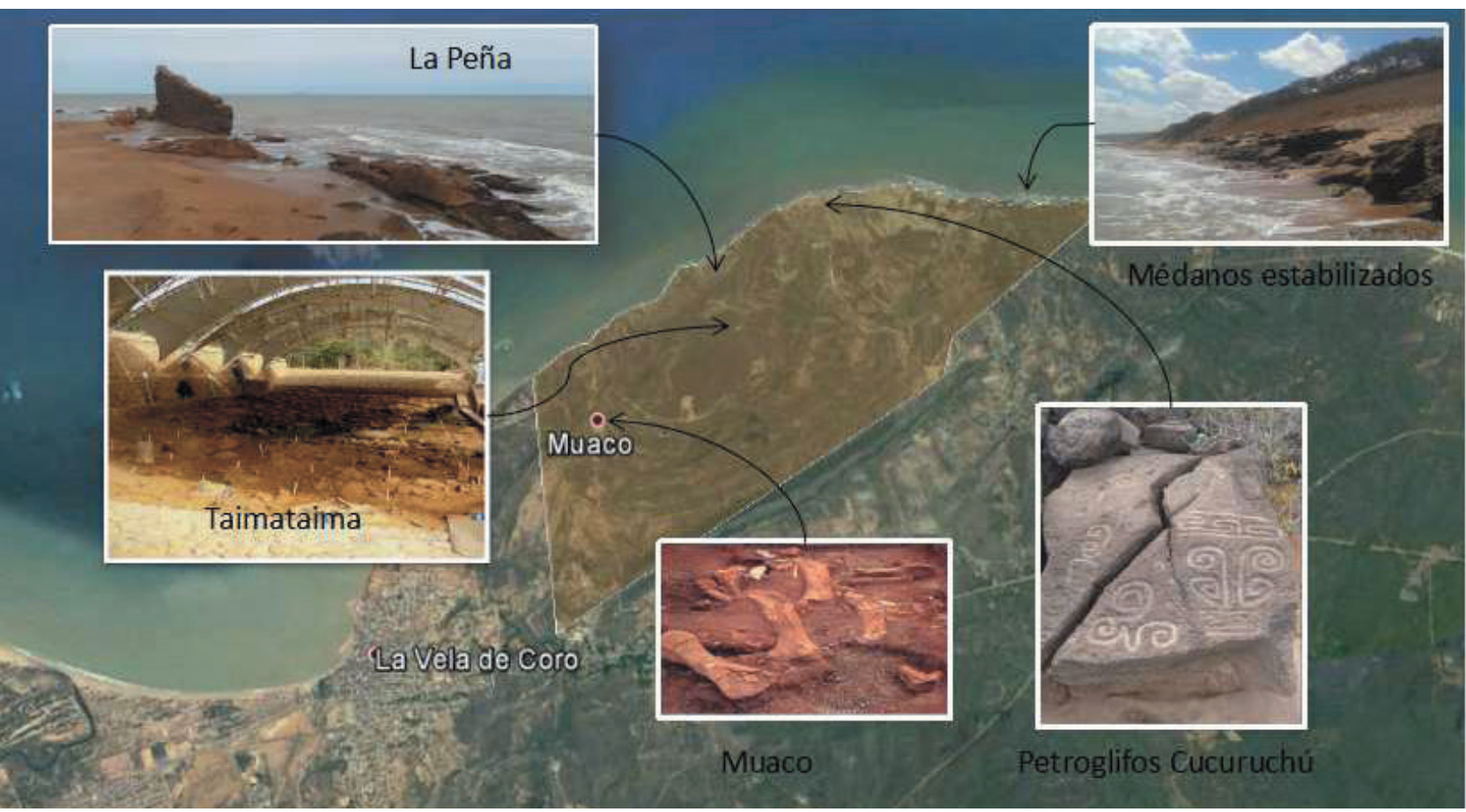




\section{Antecedentes}

Sin lugar a dudas, la figura del maestro José María Cruxent es referencia en la población de Taratara, personaje singular que discernió rápidamente las potencialidades de la comunidad y guio la conquista de un futuro cargado de mejoras en la calidad de vida de sus habitantes. Desde su primera visita en la década de 1960, este arqueólogo catalán vio con interés la riqueza invaluable presente en el pueblo de Taratara y sus inmediaciones. Una de las primeras acciones que tomó "El Musiu”, como cariñosamente le llamaban, fue el rescate de la técnica tradicional de la artesanía en barro, legado caquetío de estas tierras, datos que logró publicar en sus obras Notas - Ceramología (1980) y Loza popular falconiana (1988).

Posteriormente reunió a los artesanos y los agrupó para formar la escuela-taller del barro, con lo que garantizó un oficio rentable a sus vecinos. El éxito de esta propuesta dio apertura en 1986 al museo-taller "Ángel Segundo López”, adscrito a la Universidad Nacional Experimental Francisco de Miranda (Unefm), como un sitio para el encuentro y formación del conocimiento. A la par de estos logros continuó su labor arqueológica, que vio culmen al encontrar en el citado manantial de Taimataima una pelvis fósil de un joven mastodonte con la singularidad de poseer marcas hechas por un instrumento cinegético. El excepcional descubrimiento marcó un antes y un después, por ser capaz de orientar la reconstrucción histórica de las oleadas iniciales migratorias humanas existentes en nuestro país y en el continente americano.

Más de 25 años dedicados a la arqueología en Venezuela le fueron honrados en 1987 al otorgarle el Premio Nacional de Ciencia por el Consejo Nacional de Investigación de Ciencia y Tecnología (Conicit), hecho que recuerda con mucho cariño la comunidad al citar la anécdota de que el homenajeado puso como condición recibir el premio en Taratara, por lo cual logró movilizar al ministro y al equipo logístico del Conicit desde la ciudad de Caracas. Con este estímulo inició el nuevo proyecto de un museo in situ en Taimataima, obra de gran envergadura al que dedicó los últimos años de su vida; lamentablemente murió meses antes de su inauguración la cual se llevó a cabo en agosto de 2005.

Los primeros años de funcionamiento del Parque Arqueológico y Paleontológico de Taima- taima tuvo la cooperación de la Unefm, a través del Centro de Investigaciones Antropológicas, Arqueológicas y Paleontológicas (Ciaap), citado por Reyes (2015, p. 99) en la entrevista que realiza María Luisa Muñoz (2005) al profesor Orangel Aguilera para la Agencia Bolivariana de Noticias ABN: "El parque apenas se inaugura y comenzamos con buen pie, porque nuestro piso es muy sólido, ya que tenemos excelentes fundamentos desde el punto de vista de la potencialidad científica y académica”. Declara Aguilera que el proyecto se apoya en la coexistencia con los habitantes de las zonas adyacentes como La Vela, Taratara, Muaco, Carrizal y La Aguada, poblaciones del Municipio Colina, de esta entidad, otorgando esta declaración la relevancia que ha de tener la comunidad en la gestión del parque, sobre la cual recae la corresponsabilidad en la custodia y mantenimiento del lugar.

En torno a la inauguración del parque se efectuaron algunas exposiciones y actividades con miras a involucrar a la comunidad y al público en general, entre esas actividades se citan: "El mamut y sus parientes de Falcón” (agosto-enero, 2005), "Falcón, tierra de colosos" (septiembre, 2005), el Encuentro Internacional sobre Paleoambiente y Poblamiento Temprano en Taimataima (septiembre, 2005) y las Jornadas de Protección y Defensa del Patrimonio Cultural (noviembre, 2005).

El Instituto de Patrimonio Cultural (IPC) concibió el aspecto funcional del parque como un acto de corresponsabilidad con la comunidad, sin embargo, no se tomó en cuenta el alto índice de marginación económica del sector, y que si bien el parque es un legado cultural sustancial para la comunidad, este tiende a desaparecer por falta de planes adecuados; por lo cual, Schneider (2010, p. 95) refiere que los actores sociales no son conscientes de la importancia que desempeñan en la generación del valor significante requerido para la conservación del patrimonio cultural.

En cuanto a las actuaciones realizadas en Taratara y sus áreas de influencia en lo referente a la investigación científica, se observa que son obra absoluta del maestro José María Cruxent, y que justamente al desaparecer él físicamente lo hicieron también sus acciones. Se reconoce su querencia por estas tierras, pero quizá se puede apuntar sobre su gestión en su práctica investigativa en la arqueología falconiana el no haber formado un equipo de trabajo sólido y compro- 
metido, lejano del protagonismo o mercantilismo científico, que pudiera darle continuidad a esta frágil herencia.

Otro punto resaltante en el decaimiento del parque es el desempeño administrativo, técnico y científico de las instituciones que actuaban como responsables de la sustentabilidad de la propuesta original entregada por J. M. Cruxent. Por un lado, la Unefm, encargada de la investigación científica, y por otro, el IPC, administrador del mismo, iniciaron una discordia interna y dejaron a la suerte de los vecinos el funcionamiento del parque.

\section{Metodología}

Con el fin de implementar acciones pedagógicas que redunden en el rescate, conservación y gestión del patrimonio cultural y natural, así como del acervo arqueológico y paleontológico presente en la poligonal del parque Taimataima, se diseñaron una serie de actividades estratégicas que motivaran a la comunidad y a aquellas instituciones que sumaran en el voluntariado comprometido con este legado histórico. Como punto de inicio se propone un marco teórico que permita en la praxis utilizar un lenguaje unísono en el que se le asigna al patrimonio un carácter social, participativo y dinámico que se conceptualiza como un conjunto de signos y significantes que continuamente son interpretados por las comunidades involucradas con el parque, asi se logra en este espectro geográfico transformar un concepto en un valor agregado dada su estimación, importancia y aceptación.

Las actividades formativas de sensibilización patrimonial puestas en práctica en la comunidad se desarrollaron en cuatro fases, en la primera se logró conformar el equipo de trabajo y planificar actividades, en la segunda se definió la muestra con la que se trabajó, en la tercera se definieron cuatro momentos para la ejecución de encuentros educativos, y en la última se sistematizó y evaluó lo llevado a cabo en las comunidades de influencia del parque. La estructura de trabajo se detalla a continuación:

1. Fase preliminar (diagnóstico): se proponen algunas pautas para revisar cuál era la conceptualización que tenía la comunidad sobre el término patrimonio, en función de sus intereses. En esta primera fase la participación de la comunidad se circunscribe a la recolección de datos e inventario del estado del parque y del museo Ángel Segundo López y cómo ellos han internalizado el término patrimonio y el tratamiento otorgado a estos dos espacios a través del tiempo. Se conformó un equipo integrado por miembros de la Unefm y la comunidad de diversos perfiles profesionales, que pudiera orientar la actividad en áreas científicas y humanísticas de acuerdo con las exigencias que presentaban los consejos comunales para la sensibilización de los miembros de la comunidad a partir de los valores que estos tienen del conjunto patrimonial.

El equipo de trabajo estuvo integrado por: Mary Céspedes, vocera del consejo comunal Taratara; Pedro Céspedes, vocero del consejo comunal Taratara; Yajaira Trompiz, vocero del consejo comunal Carrizal-Muaco; Andrés-Eloy Reyes, encargado de la museografía y curaduría; Gina Ojeda, enlace de la Universidad Nacional Experimental Francisco de Miranda, institución encargada de la administración del Museo Ángel Segundo López de Taratara; y Miguel ZavalaReyes, quien viene ejecutando la investigación sobre la reconstrucción geohistórica de Tararata y se encargó de facilitar los talleres de sensibilización patrimonial y museografía.

Este equipo de trabajo diseñó el plan de acción; la actividad central fue una exposición en el museo titulada "Cruxent y el primer hombre americano en Falcón” para ser presentada en el marco del décimo aniversario del fallecimiento del maestro José María Cruxent.

2. Segunda fase (selección de la muestra): se tuvo en cuenta la inestabilidad de la comunidad para acometer las actividades necesarias de difusión y conservación de este patrimonio, y la fluctuante motivación debido a que no ha recibido un estímulo de parte de los órganos competentes gubernamentales, y a que estos no ha aportado recursos organizativos ni financieros.

Sin embargo, siempre esta ha dado evidencia de tener un conocimiento de la riqueza patrimonial existente en la zona. Esta situación cognitiva fue lo que permitió activar un procedimiento de muestreo intencionado con el fin de conformar los grupos participantes para la sensibilización, a partir del total de la población existente en el área de influencia del Parque Arqueológico y Paleontológico Taimataima. Así se seleccionaron dos grupos muestréales: los voceros de los consejos comunales y los estudiantes de tercer a sexto grado de Educación Primaria de las escuelas de 


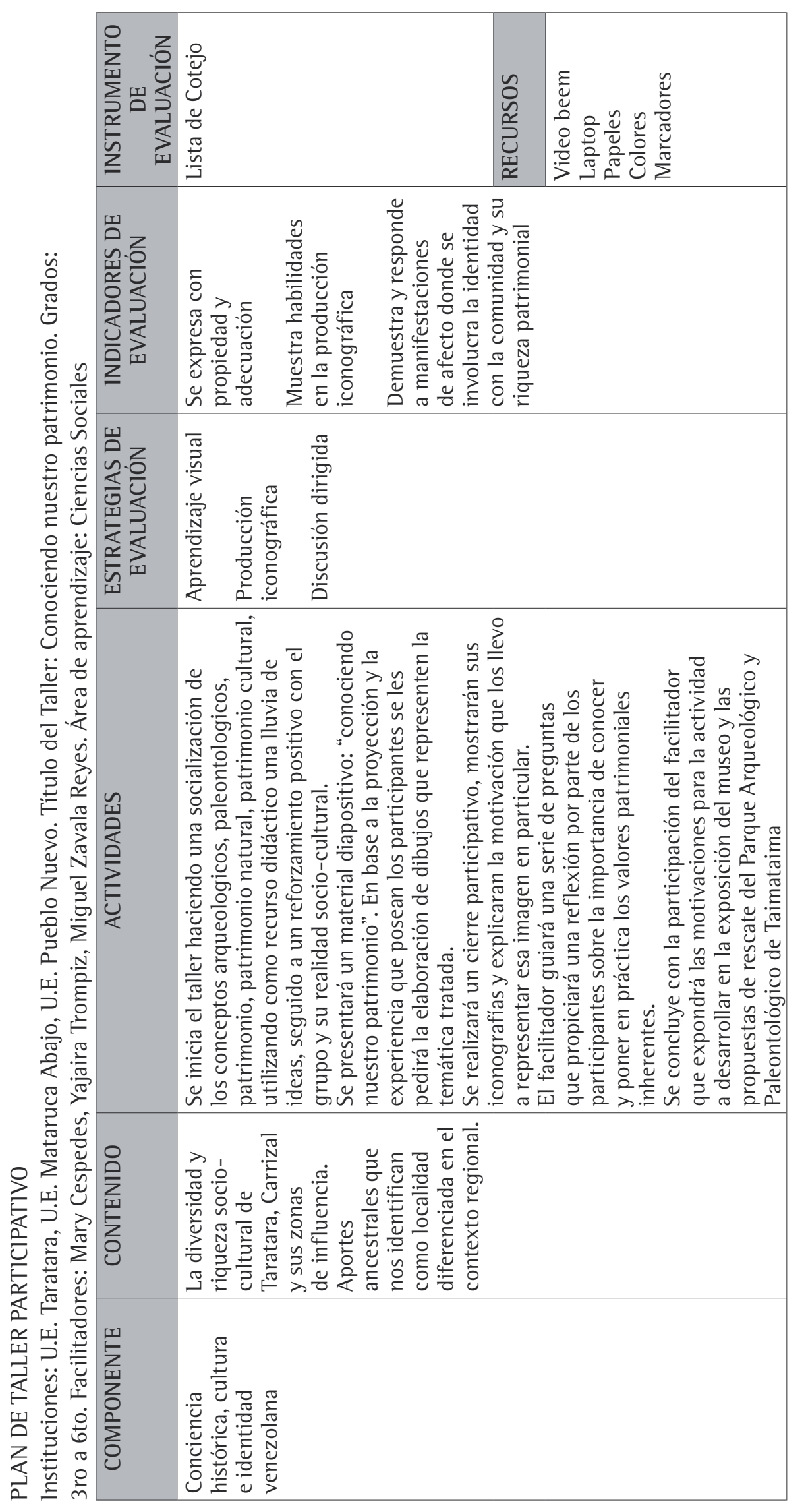

Figura 3:

Cuadro 1. Plan del

taller participativo:

"Conociendo nuestro patrimonio"

Fuente:

Elaboración propia 
los sectores Taratara, La Aguada, Pueblo Nuevo y Mataruca Abajo.

La actividad de cierre se realizó en el museo, allí se integraron las dos muestras poblacionales ya mencionadas, a las que se unieron los visitantes de la exposición, grupo conformado por la población total que asistió al museo ya que la invitación fue de carácter abierto y sin costo alguno.

3. Tercera fase (actividad formativa): en esta fase solamente se convocaron los grupos del consejo comunal y los estudiantes de las escuelas para participar en un taller titulado "Conociendo nuestro patrimonio", el objeto fue proporcionar información acerca del valor e interpretación del patrimonio natural y cultural de la localidad. Para su puesta en práctica se diseñó el siguiente esquema de trabajo:

3.1 Estructura del taller. De acuerdo con las características de la muestra se delineó un taller pedagógico de apropiación social dictado por separado a los dos grupos. Ambos talleres iniciaban con un módulo de contenido común para los dos grupos, en el que se presentaban los conceptos básicos de arqueología, paleontología y patrimonio, y el legado del maestro José María Cruxent: los fósiles encontrados pertenecientes a la extinta megafauna y la presencia del paleoindio.

Un segundo módulo se estructuró por se-

Actividades previas a la exposición: performance, coro estudiantil, teatro de títeres

Fuente:

Elaboración propia parado para cada grupo, su contenido versaba sobre: localización y registro de sitios arqueológicos, técnicas apropiadas para el rescate, el saber arqueológico comunitario y la función de los mu- seos comunitarios. En el caso de los estudiantes el recurso instruccional fue la iconografía. En los dos talleres se hizo un cierre cognitivo dirigido a reflexionar en la relación de la comunidad con su paisaje, identidad, memoria y tradición oral, y también en otras formas de valorar su patrimonio.

3.2 Vinculación a la realidad que se pretende transformar. Partiendo de la premisa "el conocimiento de la realidad es cognoscible”, se realizó una visita previa a las escuelas y vocerías de los consejos comunales para plantearles a los participantes lo que se ejecutaría en la siguiente semana, y se les motivó para que indagaran en sus hogares o con otros miembros clave acerca del patrimonio en la comunidad, esto con el fin de intensificar las relaciones interpersonales e inducir a un reconocimiento natural y espontáneo sobre las riquezas de su entorno.

3.3 Despertando verdadero interés en los participantes. En este tercer momento se buscaba obtener respuestas que mostraran lo que ha sido la gestión comunitaria del patrimonio cultural, a través de la información averiguada por los participantes, para determinar las causas que desencadenaron la falta de motivación y el decaimiento de la dinámica que en un inicio se llevó tanto en el parque como en el museo.

3.4 Explorando e identificando las ideas in- tuitivas y habilidades de los participantes. En este último momento se estableció la iconografía como recurso didáctico, de tal manera que los facilitadores indujeran a los participantes a construir

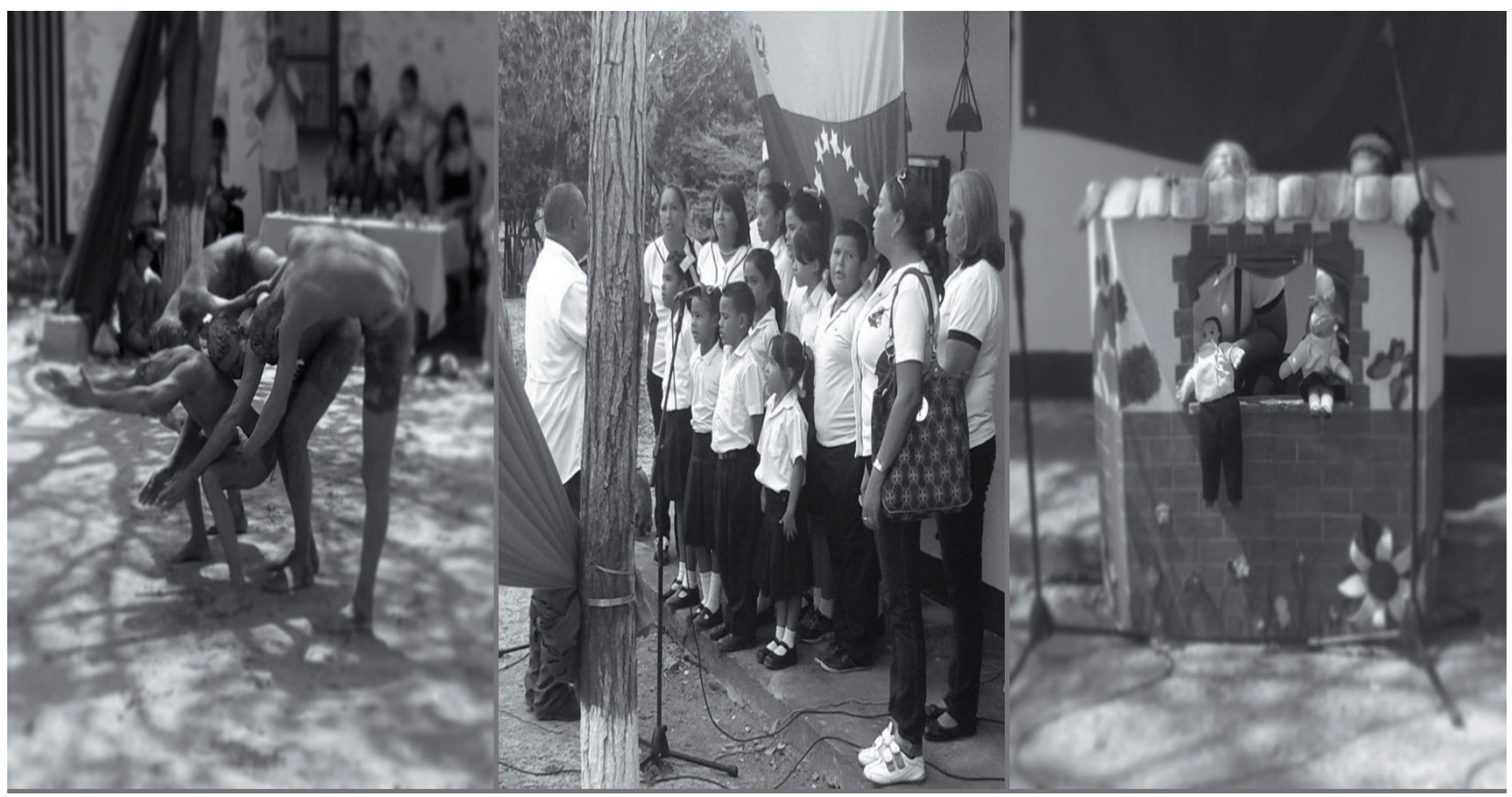


un aprendizaje significativo, planteamiento que Coarite (2010) toma de David Ausubel, teórico del cognoscitivismo. Mediante una expresión plástica los participantes deberían dar razón de lo aprendido en el taller, particularizando la experiencia y evaluando de manera general lo entregado. Como estrategia de participación se decidió incluir esta muestra pictórica en la exposición del museo para asegurar la asistencia de los estudiantes y sus padres o representantes.

4. Cuarta fase (actividad difusiva-reflexiva): la inauguración de la exposición "Cruxent y el primer hombre americano en Falcón”, se realizó el 23 de julio de 2015. Como antesala a la apertura estuvo la interpretación del Himno Nacional con la participación del coro de la Escuela de Taratara, cantos locales, declamación de poesía y una muestra de teatro de títeres. Toda esta antesala correspondió a la participación de las escuelas representadas por los estudiantes y sus padres.

La apertura de la exposición se hizo con la intervención de bailarines de la zona, entre bailes y performance contemporáneo, dirigidos por Carlos Soto, vocero de cultura del consejo comunal de Taratara; estos movimientos representaban el nacimiento del hombre a través del barro y la superioridad de los habitantes ante la megafauna, la representación de este género de la fauna en el baile se convirtió en un símbolo que invitaba a los presentes a entrar a la sala de exposición.

La exposición logró envolver en un realismo mágico al visitante que durante el recorrido viajaba en el tiempo para conocer la vida del paleoindio de Falcón y los vestigios que de esta detallaban los prototipos expuestos. Se resalta la relación museo-educación popular que en esta comunidad implicó la posibilidad de encontrar en el recinto cultural un aliado que ofreció herramientas para reafirmar su identidad, elevar su autoestima y asumir su condición de ciudadanos.

La musealización de la muestra expositiva estuvo recreada en 20 ambientes que mostraban las teorías de poblamiento americano, se resaltaron las muestras que daban testimonio de su haber en territorio falconiano. La exposición inició con muestras informativas de los diferentes eventos biogeológicos que permitieron el desarrollo de la vida en la tierra, pasaron por el poblamiento de América y detallaron los hallazgos arqueopaleontológicos en el parque arqueológico y paleontológico de Taimataima.
A continuación se enumera la guía expositiva:

Panel número 1. El gran intercambio biótico americano. Informa los eventos biogeológicos ocurridos en la tierra como base fundamental para explicar la paleodiversidad faunística en los yacimientos paleoarqueológicos del Parque Taimataima.

Panel número 2. El poblamiento de América. Refiere las hipótesis del poblamiento temprano de América y la importancia del sitio de Taimataima.

Panel número 3. El Jobo y el Paleoindio. Detalla los hallazgos realizados en el occidente del estado Falcón, que define el estilo de puntas líticas denominado Joboide y su relación con el paleoindio.

Panel número 4. El hallazgo de Taimataima. Se muestra una breve reseña histórica de lo que fue el hallazgo de Taimataima y su importancia arqueopaleontológica.

Paneles número 5, 6 y 7. El mastodonte. Paneles explicativos que muestran huesos fósiles de estos animales hallados principalmente en el sitio de Taimataima.

Paneles 8 y 9. El megatherio. Muestra de huesos fósiles de los llamados vulgarmente perezosos gigantes, colectados la mayoría en el sitio quebrada Ocando.

Panel número 10. El gliptodon. Se expone una completa reseña de los acorazados gigantes mediante la exhibición de huesos fósiles de los sitios de Taimataima y Muaco.

Panel número 11. La macrauchenia. Muestra de huesos fósiles colectados por José María Cruxent en diferentes yacimientos del Parque Taimataima.

Paneles 12 y 13. Los herbívoros. Se reseñan las especies de herbívoros de mediano tamaño: caballo sudamericano, venado matacán, tortuga, toxodonte y paleollama mediante fósiles originales de los diferentes yacimientos que componen el Parque Taimataima.

Paneles 14 y 15. Los carnívoros. Se exponen reseñas gráficas sobre algunas especies de carnívoros de mediano y gran tamaño: lobo terrible, mapurite o zorrillo, jaguar y oso de rostro corto. Se emplean fósiles originales de los diferentes yacimientos que componen el Parque Taimataima, además de réplicas elaboradas en yeso.

Panel 16. Biografía de José María Cruxent. Se incluyen las obras bibliográficas del arqueó- 
logo homenajeado, así como los datos más resaltantes de su nutrida biografía.

Panel 17. El Hesperogavialis cruxenti. Se muestra una mandíbula y fragmento del rostro de una especie de cocodrilo gavial fósil, colectada en el área de Urumaco, en el estado Falcón, y que lleva el nombre cruxenti en homenaje al Dr. Cruxent.

Panel 18. Los científicos que trabajaron con el Dr. Cruxent. Se incluye una breve reseña de algunos de los científicos que trabajaron en el sitio de Taimataima.

Panel 19. El Parque Taimataima. Muestra los datos básicos sobre el Parque Taimataima, sus áreas de influencia y su poligonal.

Panel 20. Las riquezas del Parque Taimataima. Se complementa la exposición con un compendio de piezas arqueológicas y paleontológicas colectadas en diferentes sitios dentro del parque y de diferentes periodos geológicos e históricos.

Cajón 1. Se exhibe una réplica de la pelvis del mastodonte que fue hallada en el sitio de Taimataima, con una punta lítica en su interior, como muestra de haber sido cazados por los primeros habitantes del continente americano.

Cajón 2. Se exhibe una imagen en tamaño

Figura 5: Aspectos varios durante la exposición: “Cruxent y el primer hombre americano en Falcón"

Fuente: Elaboración propia real del Dr. José María Cruxent, con una serie de objetos que simulan una pequeña área de excavación en su interior.

Vitrina central. Un diorama a escala muestra una escena de cacería, recreando lo que pudo haber ocurrido en el sitio de Taima- taima durante finales del pleistoceno o principios del holoceno.

5. Quinta fase o fase final (evaluación, sistematización y utilización de las competencias adquiridas). El proceso de evaluación no solo se ejecutó en esta quinta fase, sino que se dio de una manera continua a medida que se fueron ejecutando las anteriores. Así, en cada actividad se hizo un trabajo reflexivo con los miembros de la comunidad, el cual generó un mayor impacto con la muestra expuesta en el museo del pueblo al ver retratada en las vidrieras la historia como parte de su vida misma, logrando activar situaciones de aprendizaje grupal-cooperativo-reflexivo para la revalorización del patrimonio cultural.

$\mathrm{Al}$ establecer el guion museográfico se concibió el espacio físico como una especie de confesionario en el que exponían los problemas que aquejaba a su gente y ofrecía a su vez herramientas valorativas, esto permitía que cada usuario, al conocer su pasado, pudiera organizar su presente $y$, posiblemente, visualizar el futuro que debía construir.

Por lo anterior se reconoce que esta compleja experiencia logró en cada participante una mejor comprensión en su individualidad, a través de lo plasmado en las imágenes los jóvenes expresaron con la plástica lo internalizado en el proceso formativo, así como los vecinos en general, durante la apertura de la exposición, asumieron la logística y otras acciones y contribuyeron con responsabilidad, apoyo y colaboración al mantenimiento de las instalaciones del museo. Se

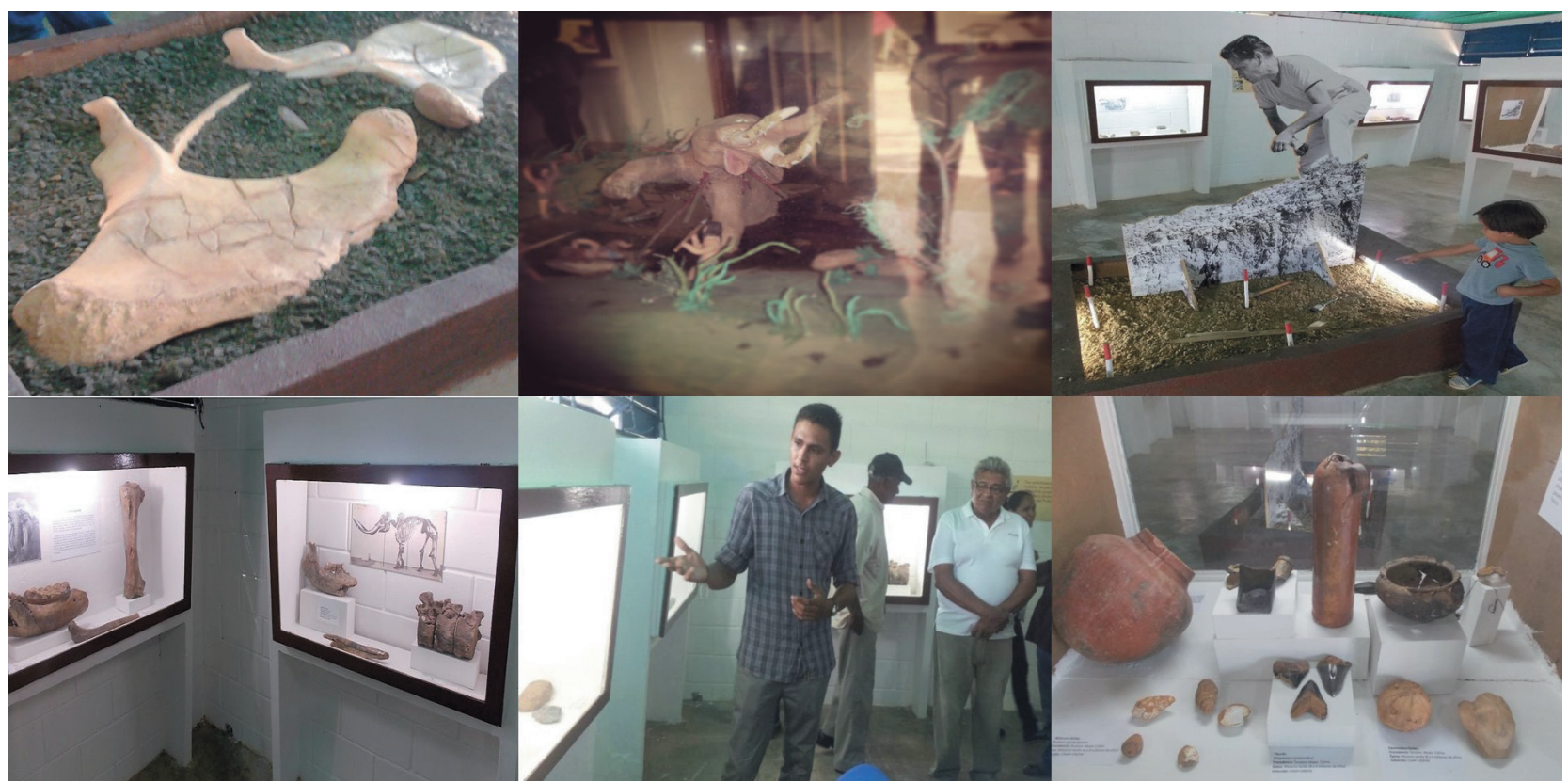


reconocieron como seres sociales que poseen de forma inalienable deberes y derechos, y que de acuerdo con la tesis de Freire (1978) "el hombre no es objeto de nada ni nadie, es sujeto de sí mismo, es un ser consciente cuyo fin es el mismo. Es un ser capaz de reflexionar, criticar y transformar su realidad", se obtuvo, por tanto, la respuesta de vida del nuevo ciudadano ante la valoración de su patrimonio natural y cultural como parte de su propia identidad.

En la etapa posterior a las actividades formativas, luego de culminada la planificación y pasados aproximadamente tres meses de la exposición en el museo, el equipo de trabajo fue convocado por los consejos comunales de Taratara y CarrizalMuaco para agradecer las acciones que se habían desarrollado. En esta socialización se pudo apreciar que aunque estábamos frente a los mismos dirigentes vecinales estos afrontaban su realidad de forma distinta, y que el aprendizaje obtenido les hacía trazar nuevos estadios de desarrollo comunitario. Los voceros congregados mostraron un plan de acción diseñado por ellos mismos, en el que planteaban como línea macro de la gestión comunitaria la atención a las instalaciones del parque, propuesta que sería presentada ante el IPC.

\section{Discusión y conclusiones}

La propuesta del trabajo con las comunidades que integran el Parque Arqueológico y Paleontológico Taimataima brindó un espacio para que sus habitantes tomaran conciencia de su identidad y de la riqueza patrimonial con que cuentan, se parte de la idea de que lo desconocido no se puede reconocer ni tomar como pertenencia, y que lo que no se posee y se apropia no se conserva. Los participantes expresaban que era la primera vez que asistian porque en eventos anteriores no habían sido tomados en cuenta. Su participación en las actividades, donde se desempeñaron los padres junto con sus hijos, mostró la relación de familiaridad y pertenencia en lo que se ejecutaba.

Los niños, niñas y adolescentes de las escuelas que conforman el área de influencia del parque lograron expresar gráficamente, como ejercicio de evaluación, lo que ellos identificaban y valoraban como patrimonio natural y cultural, con esta herramienta didáctica se captó el compromiso adquirido por ellos al conocer esta riqueza presente en su comunidad.
Sin embargo, es necesario acotar que hace falta un estímulo constante en la comunidad a fin de darle continuidad a las propuestas iniciadas. Hacer accesibles los resultados obtenidos propicia la generación de insumos para las posteriores propuestas formativas.

Otro aporte fundamental a la discusión fue el papel de los consejos comunales, que tomaron sus recursos patrimoniales, naturales y culturales como eje que impulse y transforme su futuro, apoyados, como lo indica el ya citado Noval (2012, p. 12), "en la identidad y cohesión que les pueda dar ese patrimonio, fortalecer, organizar y dinamizar la participación de la comunidad en las tareas que directamente o indirectamente afectan a los bienes culturales". Los consejos comunales de Taratara y Carrizal-Muaco se mostraron motivados en fortalecer una relación institución-comunidad, es el caso puntual del aporte académico que puede seguir brindando la Unefm, y también formar redes que permitan aunar esfuerzos con otras instituciones, como la Universidad Central de Venezuela (UCV), el Instituto de Investigaciones Científicas (IVIC), Universidad de Los Andes (ULA) que en su formación en pregrado y posgrado se vinculen con la carrera de antropología.

La participación resultó ser una buena práctica que influyó en el fortalecimiento de la identidad de los habitantes del eje TarataraCarrizal-Muaco, y en la sostenibilidad de las acciones emprendidas. La exposición en homenaje a Cruxent dio resultados positivos pues se logró motivar a la comunidad y hacerles sentir que en efecto son parte valiosa y fundamental para la conquista de los logros planteados; con esta actividad se generó un espacio cognitivo grupalcooperativo-reflexivo para la revalorización del patrimonio natural y cultural.

Otro aspecto que se puede resaltar, y que en el diagnóstico realizado se centraba en la desmotivación de los vecinos del sector, era el deplorable estado en que se encontraba el parque Taimataima, que en palabras de Reyes (2015, p. 100) mostraba una infografía y replicas deterioradas, un espacio invadido por la fauna silvestre, ausencia de personal que atienda al visitante, deterioro total del pabellón que se encuentra a la entrada del paso hacia la excavación, desaparición casi total de los restos de la fauna excavada por Cruxent.

Ante esta situación, los integrantes de los consejos comunales lograron reunir a los diferentes actores relacionados, personal del IPC, 
Unefm - Ciaap, con el propósito de reactivar definitivamente el parque mediante una gestión patrimonial comunitaria y un acompañamiento continuado del IPC en los diferentes procesos de gestión.

Entre los productos turístico-culturales que la gestión comunitaria pretende implementar están un sistema de información e interpretación para la sostenibilidad del patrimonio integrado por senderos con carteles de interpretación del patrimonio cultural y natural y exposiciones itinerantes que muestren a la comunidad el modelo de diseño y los resultados de los talleres pedagógicos de apropiación social.

\section{Referencias}

Coarite M. (2010). La icnografía como recurso didáctico para la enseñanza de la historia. Revista del Museo Nacional de Etnografía y Folklore, 1, 283-292.

Cruxent, J. M. (1980). Notas - Ceramología. Coro: Universidad Nacional Experimental Francisco de Miranda.

Cruxent, J. M.; Durán, F. E. y Matheus, N. de J. (1988). Loza popular falconiana. Caracas: Grupo Univensa.

Freire, P. (1978). La educación como práctica de la libertad. México: Siglo XXI.

García-Valecillo, Z. (2007). Educación, patrimonio cultural y museos de arte: Espacios para la interacción social. Ponencia presentada en la 1 Jornadas Internacionales: "La dimensión educativa de los museos de arte y centros culturales" [CD-ROM]. Buenos Aires-Argentina.

International Council on Monuments and Sites [1comos] (1931). La Carta de Atenas para la Restauración de Monumentos Históricos. Conferencia Internacional de Atenas. Grecia: lcomos.

International Council on Monuments and Sites [lcomos] (1964). Carta de Venecia. Carta Internacional para la Conservación y la Restauración de Monumentos y Sitios. CIAM, Venecia: lcomos.

Noval, B. (2012). Acompañamiento a las comunidades en las gestiones y procesos de organización para la conservación de su patrimonio. IX Foro Académico de Ciencia, Creación y Restauración. México: CNPC - INAH.
Organización de las Naciones Unidas para la Educación, la Ciencia y la Cultura [Unesco] (1954). Primer protocolo a la convención para la protección de los bienes culturales en caso de conflicto armado. La Haya: Unesco.

Organización de las Naciones Unidas para la Educación, la Ciencia y la Cultura [Unesco] (1972). Convención sobre la protección del patrimonio mundial cultural y natural. París: Unesco.

Organización de las Naciones Unidas para la Educación, la Ciencia y la Cultura [Unesco] (1982). Declaration on Cultural Policies adopted by the World Conference on Cultural Policies. México: Mondiacult.

Organización de las Naciones Unidas para la Educación, la Ciencia y la Cultura [Unesco] (1990, 6 de julio). Ley aprobatoria de la Convención para la Protección del Patrimonio Mundial, Cultural y Natural de la Unesco. Gaceta Oficial de la República de Venezuela n. ${ }^{\circ} 4.191$ [Extraordinario].

Organización de las Naciones Unidas para la Educación, la Ciencia y la Cultura [Unesco] (2006). Ley Aprobatoria de la Convención para la Salvaguarda del Patrimonio Cultural Inmaterial.

Oranización de Naciones Unidas para la Educación, la Ciencia y la Cultura [Unesco] (2006, 25 de septiembre). Ley Aprobatoria de la Convención para la Salvaguardia del Patrimonio Cultural y Material, entre la República Bolivariana de Venezuela y las Naciones Unidas para la Educación, la Ciencia y la Cultura Unesco. Gaceta Oficial de la República de Venezuela n. 5.822 [Extraordinario].

República Bolivariana de Venezuela (1993, 3 de octubre). Ley de Protección y Defensa del Patrimonio Cultural. Gaceta Oficial de la República Bolivariana de Venezuela n. ${ }^{\circ} 4.623$.

República Bolivariana de Venezuela (1999, 30 de diciembre). Constitución de la República Bolivariana de Venezuela. Gaceta Oficial de la República Bolivariana de Venezuela n. ${ }^{\circ}$ 36860, marzo 24, 2000.

República Bolivariana de Venezuela (2005, 10 de junio). Resolución por la cual se declara Sitio de Interés Cultural, el área geográfica que en ella se especifica del Parque Arqueológico y Paleontológico Taimataima Gaceta Oficial de la República Bolivariana de Venezuela n. 38.206 . 
Reyes, A. (2015, enero-junio). El amor simbólicosignificativo como determinante en los procesos de conservación del patrimonio arqueológico y paleontológico, ejemplificado en el caso Taimataima. Boletín Antropológico, 33(89), 89-103.
Schneider, R. (2010, marzo). Rehabilitación, conservación y restauración de bienes culturales en comunidades marginadas. El caso de Santa María Acapulco, San Luis Potosí. Cultura y representaciones sociales, 4(8), 213-250. México: UNAM. 